\title{
Effect of Intra-amniotic Oestriol Sulphate on Uterine Contractions
}

\author{
A. I. KLOPPER,* M.D., PH.D., F.R.C.O.g. ; K. J. DENNIS,* M.B., F.R.c.s.ED., M.R.C.O.G. \\ VALERIE FARR, $\dagger$ M.D., D.C.H.
}

British Medical fournal, 1969, 2, 786-789

\begin{abstract}
Summary: The effects of oestriol sulphate on $\checkmark$ myometrial activity in a group of young primigravidae, who were at 41 or more weeks' gestation, are compared with those of a placebo in a double-blind trial. Both compounds were administered over a period of six hours directly into the uterine cavity following artificial rupture of membranes. Intra-amniotic pressure recordings demonstrated a peak in the mean intensity in uterine contractions in the oestriol-treated and placebo-treated groups at six and four hours, respectively. The length of labour tended to be shorter in those patients having greater uterine activity.
\end{abstract}

\section{Introduction}

In late pregnancy a woman excretes $20-30 \mathrm{mg}$. of oestriol in the urine every day. This is at least 1,000 times more than the vutput of a non-pregnant subject. Little is known about the role of this steroid in pregnancy or indeed whether there is any physiological activity peculiar to this compound. Such a definite increase in the production of oestriol during pregnancy occurs only in the human and in some higher primates. It is present, mainly as oestriol sulphate, in a comparatively high concentration in the foetal circulation and liquor amnii (Diczfalusy et al., 1961). Intra-amniotic injection of this conjugate is likely to be a more searching test of the physiological activity of the hormone than administration by mouth or parenterally of the free compound. An investigation of the metabolism of oestriol sulphate after its injection into the uterine cavity of women in late pregnancy (Klopper et al., 1968) showed that pharmacological doses were associated with increased uterine activity. In subsequent trials two women at term went into labour, and delivered following the injection of oestriol sulphate into the amniotic cavity. These findings therefore warranted further investigation by a blind trial against a placebo.

\section{Methods and Materials}

\section{Selection of Subjects}

The trial was done on primigravid volunteers of 18 to 25 years of age, who were normotensive and healthy but were at 41 weeks' or more gestation. In accordance with routine hospital practice, they would have had labour induced. To be included in the study only patients were selected who were certain of their menstrual history (and hence of the duration of the pregnancy), had single pregnancies, and in whom the foetal head was presenting by the vertex and was engaged in the maternal pelvis. If meconium-stained liquor was obtained when the membranes were ruptured the patient was not included in the trial.

\section{Technique}

All the inductions were done by one of us (K. J.D.). The cervix was examined, and its degree of dilatation and whether or not it was taken up and its consistency were noted. The small bag of forewaters was then ruptured with a Drew Smythe catheter, which was slipped past the foetal head inside the amniotic cavity. Sterile Portex manometric tubing with four holes at the end was then threaded through the metal instrument, which was withdrawn once the liquor had ceased to flow. The reasons for draining off the liquor were, firstly, to stimulate the onset of labour, and to test whether the subsequent myometrial activity was modified by oestriol sulphate; and, secondly, to administer oestriol sulphate in high concentrations without losing any of the injected solvent from leakage around the foetal head into the vagina.

The plastic catheter, filled with liquor, was connected by means of a two-way tap to a pressure transducer and recording apparatus and to a Palmer pump driving the plunger of a $50-\mathrm{ml}$. syringe. The pump delivered $17.5 \mathrm{ml}$. of fluid in 45 minutes. The catheter was left in situ for six and a half hours, and the intrauterine pressure was recorded for 30 minutes after artificial rupture of the membranes to obtain baseline values. Thereafter the solvent was injected for 45 minutes and a recording made for 15 minutes in each hour for the next four hours. Intrauterine recordings were then made for a further two hours. By this means either four 100 -mg. doses of oestriol sulphate or four doses of solvent vehicle only were injected into the uterine cavity. The uterine activity was expressed in Montevideo units (Caldeyro-Barcia et al., 1957), which are obtained by multiplying the number of contractions in 10 minutes (frequency) by the increase of pressure in $\mathrm{mm}$. $\mathrm{Hg}$ above the resting pressure at each contraction (intensity). An attempt was made to measure the loss of liquor which occurred after the pressure-recording was started by applying a fresh pad to the vulva every half-hour and then weighing it. The valve-like action of the engaged foetal head was effective, and in no instance did the liquor loss exceed $7 \cdot 5 \mathrm{~g}$.

\section{Design}

The oestriol sulphate, $100 \mathrm{mg}$. dissolved in $4 \mathrm{ml}$. buffered sterile neutral water, was supplied in plain ampoules by Messrs. Organon. The placebo consisted of solvent vehicle only, and was made up to the requisite volume with sterile water. Each set of 4 ampoules was identified by a code number and the material administered in a random sequence unknown to the investigators. One patient was delivered before the full six hours' observation had been completed. She was therefore not included in the final analysis and the code was inspected by an independent observer, who added a further set of ampoules of the same kind. The code was broken when 18 subjects had been treated-nine with oestriol sulphate and nine with placebo. If patients were not in labour 15 hours after the rupture of the membranes an intravenous drip of oxytocin was set up.

\section{Results}

The clinical features of labour in the treated and placebo groups are summarized in Table I. All the babies were born

\footnotetext{
* Senior Lecturer and Honorary Consultant in Obstetrics and Gynaecology, University of Aberdeen.

+ Medical Assistant in Obstetrics, Maternity Hospital, Aberdeen.
} 
TABLE I.-Clinical Features of Labour

\begin{tabular}{|c|c|c|c|c|c|c|c|c|c|c|c|c|}
\hline & \multicolumn{3}{|c|}{$\begin{array}{l}\text { Induction-Delivery Interval } \\
\text { (minutes) }\end{array}$} & \multicolumn{3}{|c|}{$\begin{array}{l}\text { Induction-Labour Interval } \\
\text { (minutes) }\end{array}$} & \multicolumn{3}{|c|}{$\begin{array}{l}\text { Length of Labour } \\
\text { (minutes) }\end{array}$} & \multicolumn{2}{|c|}{$\begin{array}{l}\text { Mean Apgar } \\
\text { Score }\end{array}$} & \multirow{2}{*}{$\begin{array}{c}\text { Mean } \\
\text { Weight } \\
\text { of Baby } \\
\text { (g.) }\end{array}$} \\
\hline & Mean & S.D. & Range & Mean & S.D. & Range & Mean & S.D. & Range & $1 \mathrm{~min}$. & $5 \mathrm{~min}$. & \\
\hline $\begin{array}{l}\text { Oestriol sulphate group } \\
\text { Placebo group }\end{array}$ & $\begin{array}{l}1,050 \\
1,041\end{array}$ & $\begin{array}{l}786 \\
383\end{array}$ & $\begin{array}{l}440-4,500 \\
437-1,550\end{array}$ & $\begin{array}{r}140 \\
93\end{array}$ & $\begin{array}{r}105 \\
59\end{array}$ & $\begin{array}{l}30-330 \\
15-180\end{array}$ & $\begin{array}{l}910 \\
948\end{array}$ & $\begin{array}{l}787 \\
415\end{array}$ & $\begin{array}{l}380-2,455 \\
267-1,590\end{array}$ & $\begin{array}{l}8 \\
8\end{array}$ & $\begin{array}{l}9 \\
9\end{array}$ & $\begin{array}{l}3,687 \\
3,091\end{array}$ \\
\hline
\end{tabular}

alive, and in terms of the Apgar score their average clinical state was the same. The mean weight of the babies in the oestriol-treated group was $596 \mathrm{~g}$. greater than that of the placebo group, and on this account the oestriol sulphate group might have been expected to have longer and more difficult labours. One baby in the placebo group and two in the oestriol sulphate group were delivered by forceps. There is no significant difference between the two groups in the mean inductiondelivery interval, the mean induction-labour onset interval, or the mean length of labour. There was no evidence of intrauterine or foetal infection in either group.

In an attempt to see whether the cervical state or the uterine activity had more effect on clinical features, such as the induction-delivery interval, an arbitrary score was given to the state of the cervix (Table II. Thus a hard, long, closed cervix was scored -3 while a soft, fully taken-up cervix $2-\mathrm{cm}$. dilated was scored +5 . There was a tendency for lower cervical scores to be associated with longer induction-delivery intervals (Fig. 1). On the other hand, there was no relation between myometrial activity and induction-delivery interval. Similarly, other investigators have reported no correlation in normal labour between myometrial activity and such clinical features, which seem to be largely affected by the state of the cervix and relative cephalo-pelvic size (Caldeyro-Barcia, personal communication).

TABLE II.-Criteria for Cervical Scoring

\begin{tabular}{|c|c|c|c|}
\hline \multirow{2}{*}{$\begin{array}{c}\text { Cervical } \\
\text { Characteristic }\end{array}$} & \multicolumn{3}{|c|}{ Cervical Score } \\
\hline & -1 & +1 & +2 \\
\hline $\begin{array}{ll}\text { Consistency } & \ldots \\
\text { Length } & \ldots \\
\text { Dilatation } & \ldots\end{array}$ & $\begin{array}{l}\text { Hard } \\
\text { Long } \\
\text { Closed }\end{array}$ & $\begin{array}{l}\text { Soft } \\
\text { Slightly " taken up" } \\
\text { Up to } 1.5 \mathrm{~cm} \text {. }\end{array}$ & $\begin{array}{l}\text { Fully "taken up" } \\
\text { More than } 1.5 \mathrm{~cm} \text {. }\end{array}$ \\
\hline
\end{tabular}

An estimate of the uterine activity, which was made during the first 15 minutes of every hour in each subject (Table III) shows that a definite increase occurred with time in the oestrioltreated group. By the last hour every subject in this group had a higher uterine activity than before the oestriol sulphate was injected. In the placebo group, however, the pattern was more irregular. The activity tended to rise in the first few hours after the artificial rupture of the membranes, but it then fell, and by the last hour six out of the nine subjects had less uterine activity than before the placebo was injected.

TABLE III.-Uterine Activity in Montevideo Units Over Six Hours After Insertion of Intrauterine Catheter

\begin{tabular}{|c|c|c|c|c|c|c|c|}
\hline \multirow{2}{*}{ Subject } & \multicolumn{6}{|c|}{ Hours } & \multirow{2}{*}{ Mean } \\
\hline & $\begin{array}{l}1 \text { (Before } \\
\text { Injection) }\end{array}$ & 2 & 3 & 4 & 5 & 6 & \\
\hline \multicolumn{8}{|c|}{. Oestriol Sulphate Group } \\
\hline $\begin{array}{r}1 \\
2 \\
3 \\
6 \\
9 \\
12 \\
14 \\
15 \\
17\end{array}$ & $\begin{array}{r}39.0 \\
32.5 \\
75.3 \\
60.0 \\
162.0 \\
90.4 \\
101.0 \\
60.0 \\
64.3\end{array}$ & $\begin{array}{r}81 \cdot 3 \\
33 \cdot 3 \\
88 \cdot 0 \\
42 \cdot 7 \\
224 \cdot 7 \\
107 \cdot 7 \\
116 \cdot 9 \\
52 \cdot 7 \\
66 \cdot 3\end{array}$ & $\begin{array}{r}125 \cdot 3 \\
56.0 \\
61.3 \\
89.3 \\
160.7 \\
103.3 \\
111.3 \\
102.7 \\
74.0\end{array}$ & $\begin{array}{r}115 \cdot 3 \\
50 \cdot 7 \\
90 \cdot 0 \\
97.3 \\
244 \cdot 0 \\
109 \cdot 3 \\
126 \cdot 0 \\
80 \cdot 0 \\
84.0\end{array}$ & $\begin{array}{r}160 \cdot 7 \\
74 \cdot 2 \\
74 \cdot 7 \\
96 \cdot 3 \\
245 \cdot 3 \\
204 \cdot 3 \\
144 \cdot 2 \\
77 \cdot 0 \\
57 \cdot 3\end{array}$ & $\begin{array}{r}127 \cdot 1 \\
76 \cdot 7 \\
84.0 \\
85.3 \\
199 \cdot 3 \\
203.7 \\
154.3 \\
97 \cdot 0 \\
80.8\end{array}$ & $\begin{array}{r}108.1 \\
53.9 \\
78.9 \\
78.5 \\
206.0 \\
136.4 \\
125.6 \\
98.2 \\
78.2\end{array}$ \\
\hline Mean & $76 \cdot 0$ & $90 \cdot 4$ & $98 \cdot 2$ & $110 \cdot 7$ & $126 \cdot 0$ & $123 \cdot 1$ & $104 \cdot 0$ \\
\hline \multicolumn{8}{|c|}{ Placebo Group } \\
\hline $\begin{array}{r}4 \\
5 \\
7 \\
8 \\
10 \\
11 \\
13 \\
16 \\
18\end{array}$ & $\begin{array}{r}71 \cdot 0 \\
71 \cdot 3 \\
69.0 \\
114 \cdot 1 \\
172 \cdot 7 \\
94.0 \\
68.0 \\
71 \cdot 3 \\
56.4\end{array}$ & $\begin{array}{r}86.0 \\
126.0 \\
65.8 \\
124.0 \\
192.0 \\
63.3 \\
81.3 \\
119.3 \\
91.3\end{array}$ & $\begin{array}{r}98.7 \\
90.0 \\
51.0 \\
66.0 \\
182.7 \\
88.7 \\
65.3 \\
133.3 \\
118.7\end{array}$ & $\begin{array}{r}119.3 \\
97.3 \\
66.2 \\
79.2 \\
157.3 \\
122.7 \\
69.0 \\
180.0 \\
118.7\end{array}$ & $\begin{array}{r}112 \cdot 3 \\
59 \cdot 5 \\
51 \cdot 2 \\
85 \cdot 3 \\
122 \cdot 0 \\
68 \cdot 3 \\
67 \cdot 3 \\
134 \cdot 3 \\
78 \cdot 7\end{array}$ & $\begin{array}{r}96.7 \\
52.5 \\
63.5 \\
102.2 \\
169.2 \\
63.1 \\
61.5 \\
127.6 \\
91.7\end{array}$ & $\begin{array}{r}97.3 \\
82.8 \\
61.1 \\
95.1 \\
165.9 \\
83.3 \\
68.7 \\
127.6 \\
72.8\end{array}$ \\
\hline Mean & $87 \cdot 5$ & $105 \cdot 4$ & $99 \cdot 4$ & $112 \cdot 2$ & $86 \cdot 5$ & $92 \cdot 1$ & $94 \cdot 9$ \\
\hline
\end{tabular}

The initial mean uterine activity of the placebo group was somewhat greater than that of the oestriol-treated group (Fig. 2) and this difference persisted for the first three hours. The mean uterine activity of the treated group then caught up with that of the placebo group. Thereafter the mean uterine activity of the placebo group declined while that of the oestriol-treated group rose, so that at the fifth and sixth hours the mean uterine activity of the oestriol-treated group was considerably greater than that of the placebo group. When logarithmically transformed to allow for the large variation from individual to individual these differences are statistically significant $(P>0.05)$.

In addition, uterine activity appeared to be stimulated by draining the liquor. For the purposes of Fig. 3 the uterine
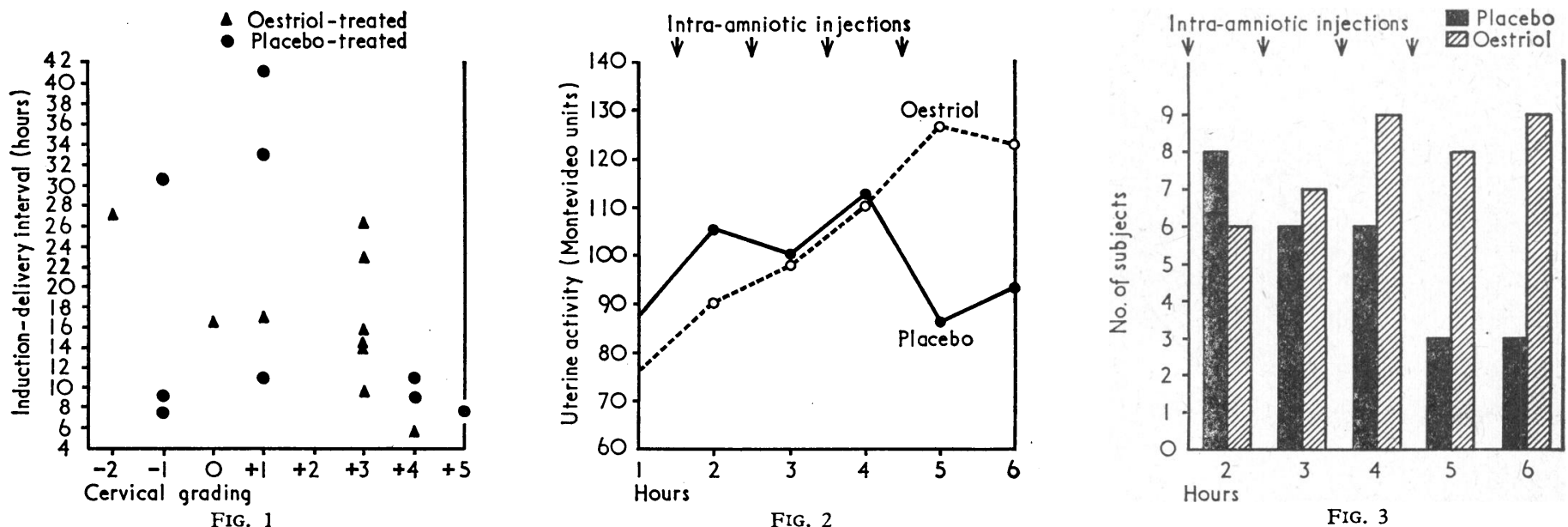

FIG. 1.-Relation between the state of the cervix and the induction-delivery interval. One subject, placebo-treated, was discarded from analysis on account of rapid delivery, but is shown in this figure. Fig. 2.- Me an hourly uterine activity of women treated by intra-amniotic oestriol sulphate or by placebo. FIG. 3.- Subjects showing increase in uterine activity above initial level immediately after draining liquor. 
activity in the first 30 minutes after passage of the catheter was taken as a baseline, and all subsequent activities compared with this. Injection of fluid alone did not appear to influence the activity, for the number of subjects in the placebo group with a greater activity than their initial one declined in succeeding hours. On the other hand, the number of subjects in the oestriol-treated group who showed an increased activity rose following repeated injections. By six hours all nine of the oestriol-treated subjects had a greater uterine activity than their initial one while only three of the placebo group did so.
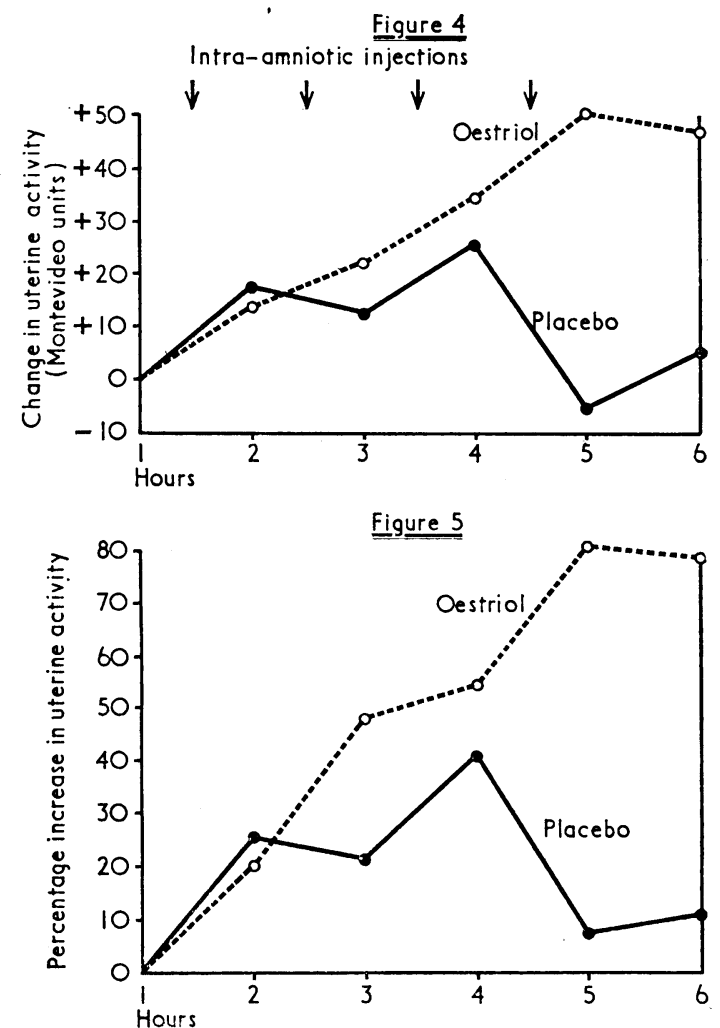

FIG. 4.- Change in uterine activity after intra-amniotic oestriol sulphate or placebo. FIG. 5.-Increase in uterine activity as a percentage of the activity before intra-amniotic injection of oestriol sulphate or placebo.

Both groups contained subjects with greatly different uterine activities (Table III), and therefore when taken together in the mean values the change in uterine activity of those subjects with a low activity is obscured by those having high scores in
Montevideo units. To some extent this can be countered by considering only the change in activity with time (Fig. 4). This figure is derived by taking the initial pretreatment value as zero and then subtracting it from subsequent measurements. In this way the absolute increase in uterine activity of each subject hour by hour is obtained, and the mean change at each hour in either group can be calculated. A somewhat greater increase in uterine activity in the oestriol sulphate groups was already apparent at the third and fourth hours (Fig. 4). At the fifth and sixth hours the greater activity following oestriol sulphate already noted is now evident as a greater mean increase of activity over pretreatment levels.

The effect of greatly varying levels of activity in different subjects can be altogether eliminated by considering the change in activity as a proportion of the initial activity before injection of oestriol sulphate or placebo. The percentage increase or decrease of each subject at each hourly interval can be calculated and the mean percentage change in each group plotted (Fig. 5). From the third hour onward the activity of the oestriol-treated group increases proportionally more than that of the placebo group. At the fifth hour the treated group has a mean activity $81 \%$ higher than before treatment while the placebo group is $7 \%$ higher. At the sixth hour the mean increase in uterine activity of the treated group is $78 \%$ and that of the placebo group is $10 \%$.

The uterine tonus (average baseline pressure between contractions) was similar in the two groups. In the oestriol-sulphate group the mean tonus before treatment was $15 \mathrm{~mm}$. $\mathrm{Hg}$. It rose to a peak of $19 \mathrm{~mm}$. $\mathrm{Hg}$ at the fourth, fifth, and sixth hours. In the placebo group the mean tonus was $14 \mathrm{~mm}$. $\mathrm{Hg}$ and rose to a peak of $17 \mathrm{~mm}$. $\mathrm{Hg}$ at the third hour.

In normal labour the frequency of contractions is not increased while uterine activity is raised, owing to the increased intensity of the contractions (Caldeyro-Barcia and Sereno, 1961). In the oestriol-sulphate group the mean frequency of contractions before treatment was 29 per hour, while in the placebo group it was 26 per hour. In both groups, however, the frequency fell slightly during the study. As might be expected from the results on uterine activity the intensity of contractions rose in both groups (Fig. 6b).

It is possible that the change in uterine activity following the passage of the catheter could be influenced by the initial state of the cervix. It might therefore be better to compare oestriol-sulphate-treated subjects with those in the placebo group whose cervix was in a roughly similar state. In the oestriol sulphate group the cervix was closed in four subjects but at least one fingerbreadth dilated in five, while in the placebo group it was closed in two subjects and open in seven.
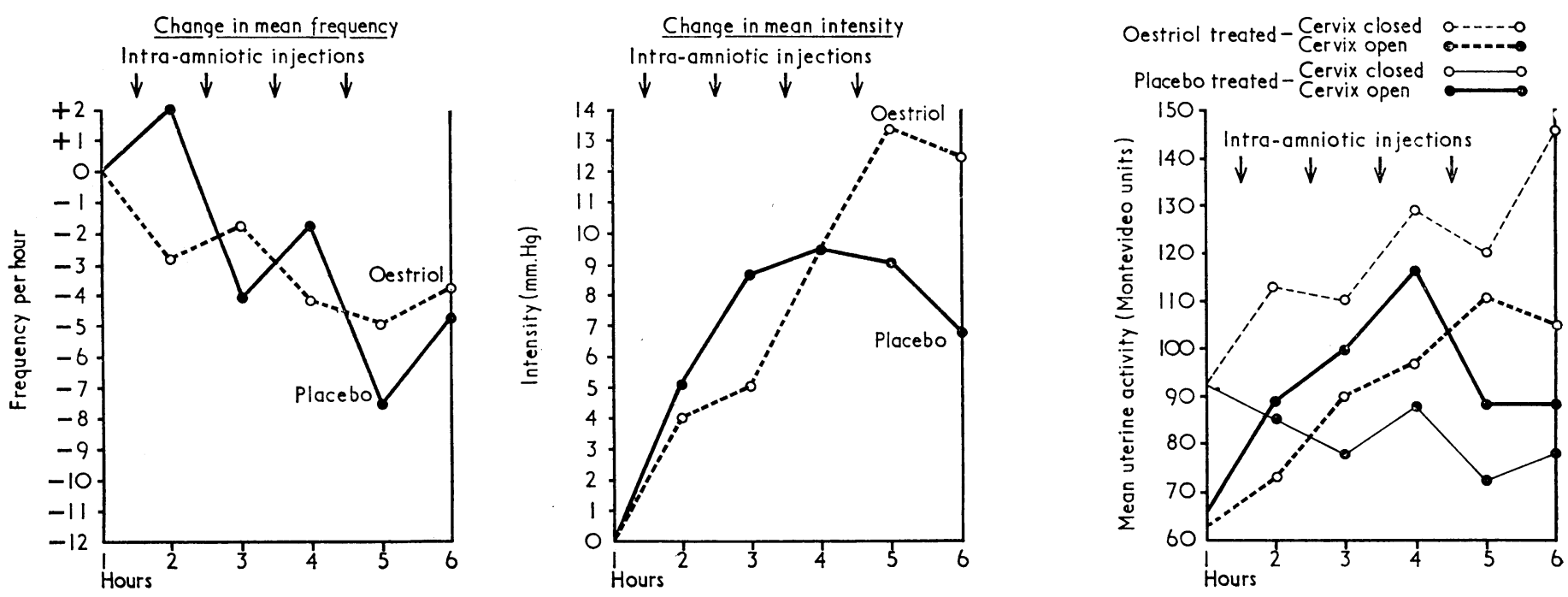

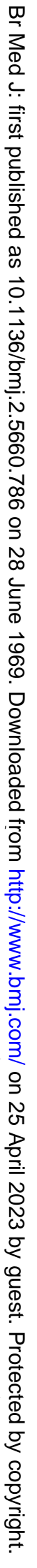

FIG. 6.-Change in (a) frequency and (b) intensity of uterine contractions after intra-amniotic injection of oestriol sulphate or placebo. FIG. 7. - Mean change in uterine activity after artificial rupture of the membra nes according to initial state of the cervix. 
The variations in uterine activity in each category are shown in Fig. 7, but, since the numbers in each group are so small, these differences are of doubtful significance.

\section{Discussion}

There are some weaknesses in the design of this study which need to be taken into account before any conclusions can be drawn from the findings. In the first place it might have been better not to rupture the membranes at all. Rupturing membranes and draining the liquor is a stimulus to the onset of labour, and in fact all our patients went into labour and delivered after six hours. The study therefore tests only whether intra-amniotic oestriol sulphate modifies uterine contractions once these have been stimulated by rupture of the membranes. To see whether oestriol in high concentration, when conveyed to the myometrium by the route which normally applies in pregnancy and in the same form as that in which it exists in vivo, has any effect on the onset of labour it would be necessary to give it by transabdominal injection before labour starts. In our view the positive findings in the present study justify such a procedure.

The control group and the test group were not the same with regard to spontaneous myometrial activity before induction and to the state of the cervix. This made it difficult to detect the effect of oestriol sulphate on myometrial activity and may have obscured a possible effect on the induction-delivery interval. These disadvantages could have been reduced had a larger number of subjects or stricter selection criteria been used. It proved difficult, however, to obtain even the present modest number of patients who satisfied all the criteria.

Attempts to define the role of oestrogens in relation to the onset of labour are not new. Pinto et al. (1967) claimed that an intravenous injection of oestradiol- $17 \beta$ stimulates labour in women at term. Our attention was first directed to a possible specific role of oestriol by the finding of Klopper and Billiewicz (1963) that women with a higher urinary oestriol excretion tended to go into labour before those with a lower output. Klopper and Dennis (1962), however, failed to find any effect from oestriol or stilboestrol given by mouth on the induction-delivery interval or on the length of labour following artificial rupture of the membranes. Thus in the light of subsequent findings the absence of any demonstrable effect following oestriol by mouth was probably due to two reasons. Firstly, oral administration of the free compound results in its prompt conjugation and excretion so that its concentration and duration of action at the myometrium are small. Secondly, though oestriol may increase myometrial activity, the results of this on the clinical features of labour may be obscured by other factors such as the state of the cervix and the cephalo-pelvic relationship. The virtue of the present study is that the actual compound made by the foeto-placental unit reaches the myometrium by the natural route. There is clear evidence that oestriol sulphate is hydrolysed by the placenta and membranes (Goebelsmann et al., 1966). Presumably the free steroid is transmitted to the maternal blood, and has its effect, if any, on the myometrium during its initial passage through the uterus and before being inactivated by reconjugation into glucosiduronate in the liver.

This is the first time that the oestriol derivative, which is present in much the largest concentration within the uterus, has been given by this route to normal women at the point of onset of labour. It is noteworthy that it should have affected uterine activity. This study, however, does not show that changes in oestriol concentration at the myometrial level play a dominant, or indeed any, part in the onset of labour.

We are indebted to our colleagues in the Aberdeen Maternity Hospital for allowing us access to their patients. The oestriol sulphate used was synthesized for us by Messrs. Organon Laboratories Ltd. and supplied by Dr. W. Tindall. We are grateful to Mr. W. Bytheway for statistical advice.

\section{REFERENCES}

Caldeyro-Barcia, R., and Sereno, J. (1961). In Oxytocin, edited by R. Caldeyro-Barcia and $\mathrm{H}$. Heller. Oxford, Pergamon Press.

Caldeyro-Barcia, R., et al. (1957). Fournal of Pharmacology and Experimental Therapeutics, 121,18

Diczfalusy, E., Cassmer, O., Alonso, C., and de Miquel, M. (1961). Recent Progress in Hormone Research, 17, 147.

Goebelsmann, U., Wiqvist, N., Diczfalusy, E., Levitz, M., Condon, G. P., and Dancis, J. (1966). Acta Endocrinologica, 52, 550.

Klopper, A., and Billewicz, W. (1963). Fournal of Obstetrics and Gynaecology of the British Commonwealth, 70,1024

Klopper, A. I., and Dennis, K. J. (1962). British Medical fournal, 2 1157 .

Klopper, A. I., Dennis, K. J., and Farr, V. (1968). British Medical fournal, 2, 158 .

Pinto, R. M., Leon, C., Mazzooco, N., and Scasserra, V. (1967). American fournal of Obstetrics and Gynaecology, 98, 540.

\title{
Radioimmunoassay of Parathyroid Hormone in Primary Hyperpara- thyroidism : Studies after Removal of Parathyroid Adenoma
}

\author{
RICHARD M. BUCKLE,* M.A., M.D., M.R.C.P.
}

\begin{abstract}
Summary : Parathyroid hormone has been measured by radioimmunoassay in eight patients with hyperparathyroidism due to parathyroid adenoma. Secretion of hormone by the adenomatas was demonstrated direct by estimating the arteriovenous gradient of parathyroid hormone across the tumours. Serial estimations following surgical removal of the adenoma showed a rapid fall in the concentration of circulating parathyroid hormone. The calculated half-life of endogenously secreted parathyroid hormone in man varied from 11.4 to $28.8 \mathrm{~min}$., with a mean of $19.8 \mathrm{~min}$.
\end{abstract}

\section{Introduction}

The radioimmunoassay of parathyroid hormone (Berson, Yalow, Aurbach, and Potts, 1963) has increased the sensitivity of its measurement, and its application in man has shown raised levels of hormone in the blood in patients with primary and secondary hyperparathyroidism (Berson and Yalow, 1966, 1968 ; Buckle, 1968a ; Melick and Martin, 1968 ; Potts, Deftos, Buckle, Sherwood, and Aurbach, 1968b.

\footnotetext{
* Consultant Physician, Department of Endocrinology, the General Hos-
} pital, Southampton, $\mathrm{SO} 94 \mathrm{XY}$. 